\title{
Corticotropin Releasing Factor Signaling in the Central Amygdala is Recruited during Binge-Like Ethanol Consumption in C57BL/6J Mice
}

\author{
Emily G. Lowery-Gionta, ${ }^{1}$ Montserrat Navarro, ${ }^{1}$ Chia Li, ${ }^{3}$ Kristen E. Pleil, ${ }^{2}$ Jennifer A. Rinker, ${ }^{1}$ Benjamin R. Cox, ${ }^{1}$ \\ Gretchen M. Sprow, ${ }^{1}$ Thomas L. Kash, ${ }^{2,3}$ and Todd E. Thiele ${ }^{1,2}$ \\ ${ }^{1}$ Department of Psychology, ${ }^{2}$ Bowles Center for Alcohol Studies, and ${ }^{3}$ Department of Pharmacology, University of North Carolina, Chapel Hill, North \\ Carolina 27599-3270
}

\begin{abstract}
A well established body of work indicates a crucial role for corticotropin-releasing factor (CRF) in neurobiological responses associated with excessive dependence-like ethanol drinking in ethanol-vapor-exposed rodents. Recent evidence demonstrates a role for CRF in the modulation of binge-like ethanol consumption by nondependent mice, a behavior that can precede ethanol dependence. The CRF circuitry that is engaged by binge-like ethanol exposure, however, is unknown. Using converging approaches, we provide evidence that, similar to ethanol-vapor-induced increases in ethanol intake, CRF signaling in the central nucleus of the amygdala (CeA) is engaged during binge-like ethanol consumption by C57BL/6J mice. Specifically, we found that binge-like consumption of an ethanol solution (20\% ethanol v/v) was attenuated by pretreatment with the CRF1R antagonists antalarmin, 4-ethyl-[2,5,6-trimethyl-7-(2,4,6-trimethylphenyl)$7 H$-pyrrolo[2,3-d]pyrimidin-4-yl]amino-1-butanol, and NBI-27914 at doses $(30 \mathrm{mg} / \mathrm{kg}$, i.p.) that did not alter nonbinge-like ethanol consumption. Binge-like ethanol consumption resulted in significant increases of CRF immunoreactivity in the CeA immediately following ethanol drinking and $18-24 \mathrm{~h}$ following ethanol removal and also blocked the ability of CRF to enhance GABAergic transmission in the CeA $18-24 \mathrm{~h}$ following ethanol removal. Pretreatment with bilateral injections of antalarmin ( $1 \mu \mathrm{g} / 0.5 \mu \mathrm{l}$ per side) into the CeA, but not the adjacent basolateral amygdala, significantly attenuated binge-like ethanol consumption. These findings suggest that CRF signaling in the $\mathrm{CeA}$ is recruited during excessive ethanol intake, before the development of dependence. We hypothesize that plastic changes in CRF signaling develop with repeated binge-like drinking episodes, contributing to the transition to dependence.
\end{abstract}

\section{Introduction}

Binge drinking defines an episode in which enough alcohol is consumed to generate blood alcohol concentrations (BECs) of 80 $\mathrm{mg} / \mathrm{dl}$ or greater (National Institute on Alcohol Abuse and Alcoholism, 2004). Binge drinking is associated with numerous adverse consequences (Read et al., 2008; Stahre et al., 2009), including an increased risk of developing alcohol dependence (Jennison, 2004; McCarty et al., 2004). As such, recruitment of mechanisms thought to underlie alcohol dependence may occur during bouts of high alcohol drinking, including alcohol binges.

Corticotropin-releasing factor (CRF) plays a key role in excessive dependence-like ethanol drinking in rats exposed to high levels of ethanol via vapor exposure, through activation of the

Received Dec. 16, 2011; revised Jan. 20, 2012; accepted Jan. 21, 2012.

Author contributions: E.G.L.-G., K.E.P., T.L.K., and T.E.T. designed research; E.G.L.-G., M.N., C.L., K.E.P., J.A.R., B.R.C., G.M.S., and T.L.K. performed research; E.G.L.-G., T.L.K., and T.E.T. analyzed data; E.G.L.-G., M.N., K.E.P., G.M.S., T.L.K., and T.E.T. wrote the paper.

This work was supported by NIH Grants AA013573, AA015148, AA017818, AA017803, AA019839, AA017668, and AA019454; a Foundation for Alcohol Research Grant; and an Integrative Neuroscience Initiative on Alcoholism-Stress Pilot Project. We thank Dr. A. Ryabinin for generously supplying CRF knock-out and wild-type mice brains.

The authors declare no competing financial interests.

Correspondence should be addressed to Dr. Todd E. Thiele, Department of Psychology, University of North Carolina, Davie Hall, CB \#3270 Chapel Hill, NC 27599-3270.E-mail: thiele@unc.edu.

DOI:10.1523/JNEUROSCI.6256-11.2012

Copyright $\odot 2012$ the authors $\quad 0270-6474 / 12 / 323405-09 \$ 15.00 / 0$
G-protein-coupled CRF-1 receptors (CRF1R) in the central nucleus of the amygdala (CeA) (Roberto et al., 2010). The CRF system does not significantly modulate ethanol consumption in nondependent rats (Roberts et al., 2000), thus leading to the hypothesis that neuroadaptations within the CRF system develop over an extended course of excessive ethanol exposure, culminating in ethanol dependence (Koob, 2003, 2009). A defining feature of this hypothesis is that CRF signaling is not crucial to maintain the initial stages of ethanol consumption that precede a dependent state (Heilig et al., 2010).

An extension of this model was revealed by several recent studies from our group that established a role for CRF signaling in maintaining binge-like ethanol consumption by nondependent animals (Sparta et al., 2008; Lowery et al., 2010). Specifically, systemic administration of a selective CRF1R antagonist, CP154,526, attenuated binge-like ethanol consumption by male C57BL/6J mice that achieved BECs of at least $80 \mathrm{mg} / \mathrm{dl}$ under control conditions. Interestingly, CRF1R signaling appeared to be exclusively recruited by excessive levels of ethanol intake, as pretreatment with CP-154,526 did not alter ethanol consumption by mice that drank moderate levels of ethanol with associated BECs of $40 \mathrm{mg} / \mathrm{dl}$ or less (Sparta et al., 2008). While these findings indicate that the CRF system modulates excessive bingelike ethanol drinking, the central site of action and the overlap 
with the CRF pathways that modulate dependence-like drinking are unknown.

The current studies were designed to test the hypothesis that the CRF neurocircuitry that underlies binge-like ethanol consumption by nondependent animals overlaps with the CRF neurocircuitry that has been implicated in dependence-like ethanol drinking. We show that three different selective CRF1R antagonists attenuate binge-like ethanol consumption, but do not affect low-level, nonbinge-like ethanol consumption. Furthermore, binge-like ethanol consumption alters CRF immunoreactivity (IR) in extrahypothalamic brain regions and alters the neuromodulatory actions of CRF in the CeA of nondependent C57BL/6J mice. We also show that binge-like ethanol consumption is attenuated by intra-CeA microinjections of a selective CRF1R antagonist, while microinjections of the antagonist into the basolateral amygdala (BLA) do not alter binge-like ethanol consumption. Together, these results provide support for the hypothesis that high levels of ethanol intake by nondependent animals, such as those observed during binge-like drinking, recruit CRF signaling in the CeA, a region that is critical to the development of ethanol dependence.

\section{Materials and Methods}

\section{Animals}

Male C57BL/6J mice (Jackson Laboratories) were 6-8 weeks of age and weighed 20-30 g upon arrival. Mice were housed individually in plastic cages and allowed to habituate to the environment for at least 1 week before experimental procedures were initiated. The animal colony room was maintained at $\sim 22^{\circ} \mathrm{C}$ with a $12 \mathrm{~h} / 12 \mathrm{~h}$ light/dark cycle (lights on at 0700 or $1300 \mathrm{~h}$ ). Mice had ad libitum access to food throughout all experiments and ad libitum access to water except during ethanol access, as noted. All procedures used are in accordance with the National Institute of Health guidelines and were approved by the University of North Carolina Institutional Animal Care and Use Committee.

\section{Drugs}

Ethanol (20\% v/v) solutions were prepared using tap water and 95\% ethyl alcohol; sucrose $(10 \%, \mathrm{w} / \mathrm{v})$ solutions were prepared using tap water and D-sucrose. The selective CRF1R nonpeptidic antagonists NBI27914 (10-60 $\mathrm{mg} / \mathrm{kg}$; Tocris Bioscience), antalarmin (30 mg/kg; Sigma-Aldrich), and 4-ethyl-[2,5,6-trimethyl-7-(2,4,6-trimethylphenyl)-7H-pyrrolo[2,3-d]pyrimidin-4-yl] amino-1-butanol (LWH-63; 10-30 mg/kg; Sigma-Aldrich) were dissolved in a $0.9 \%$ saline and emulphor (also known as Cremphor EL; Sigma-Aldrich) solution (10\% emulphor $\mathrm{v} / \mathrm{v}$ ) and delivered intraperitoneally in a $10 \mathrm{ml} / \mathrm{kg}$ injection volume $\sim 30 \mathrm{~min}$ before ethanol access. Doses were extrapolated from previous studies (Robison et al., 2004; Sabino et al., 2006; Ji et al., 2007; Kim and Han, 2009). For the intra-CeA and intra-BLA microinjections, antalarmin $(1.0 \mu \mathrm{g} / 0.5 \mu \mathrm{l}$ per side $)$ was dissolved in $0.9 \%$ saline and emulphor solution ( $5 \%$ emulphor, $\mathrm{v} / \mathrm{v}$ ) and delivered $\sim 1 \mathrm{~h}$ before ethanol access. Previous studies were used to select the dose (Robison et al., 2004; Wang et al., 2006) and injection volume (Finn et al., 2007). CRF (Tocris Bioscience) was dissolved in $\mathrm{dH}_{2} \mathrm{O}$ to a concentration of $0.1 \mathrm{~mm}$, diluted to $200 \mathrm{~nm}$ in artificial CSF (ACSF), and bath applied.

\section{Behavioral procedures}

Drinking-in-the-dark experiments. All experiments used a $4 \mathrm{~d}$ drinkingin-the-dark (DID) procedure that has been used previously to generate high levels of ethanol intake that are associated with BECs in excess of 80 mg/dl (Rhodes et al., 2005, 2007; Sparta et al., 2008; Lowery et al., 2010). On days $1-3$, beginning $3 \mathrm{~h}$ into the dark cycle, water bottles were removed from all cages and replaced with bottles containing a $20 \%(\mathrm{v} / \mathrm{v})$ ethanol solution. Mice had $2 \mathrm{~h}$ of access to ethanol, after which ethanol bottles were removed from cages and water bottles were replaced. The same procedure was followed on day 4 except that ethanol access was extended to $4 \mathrm{~h}$. Immediately following $4 \mathrm{~h}$ ethanol access on day $4, \sim 10$ $\mu \mathrm{l}$ of blood were collected from the tail vein of each animal. Blood samples were centrifuged, and $5 \mu \mathrm{l}$ of plasma were analyzed for BECs using the Analox Alcohol Analyzer (Analox Instruments). For all experiments involving pretreatment with drug on day 4 , drug treatment groups were equated based on ethanol consumption on days $1-3$. For all experiments involving multiple cycles of DID procedures, each cycle was separated by $3 \mathrm{~d}$. To assess the specificity of experimental manipulations to binge-like ethanol consumption, sucrose control studies and nonbinge-like ethanol consumption control studies were conducted. Briefly, sucrose control studies were conducted following the DID procedure similar to ethanol DID procedures except that $10 \%$ sucrose $(\mathrm{w} / \mathrm{v})$ solution was presented in place of $20 \%$ ethanol solution. Nonbinge-like ethanol control studies were conducted using similar procedures to DID, except that access to $20 \%$ ethanol began $3 \mathrm{~h}$ into the light portion of the light/dark cycle.

Perfusion, brain preparation, and immunohistochemistry procedures. Immunohistochemistry procedures were based on those routinely used in our laboratory (Thiele et al., 1996, 1997, 2000; Hayes et al., 2005). Mice were perfused transcardially with $0.1 \mathrm{~mm}$ PBS ( $\mathrm{pH} 7.4$ ) followed by $4 \%$ paraformaldehyde in phosphate buffer immediately following ethanol access on day 4 of the final DID cycle or $18-24 \mathrm{~h}$ following ethanol access on day 4 of the final DID cycle. The brains were collected and postfixed in paraformaldehyde for $48 \mathrm{~h}$ at $4^{\circ} \mathrm{C}$ and then transferred to PBS. The brains were cut using a vibratome into $40 \mu \mathrm{m}$ sections and stored in cryopreserve until the immunohistochemistry assay. Sections were then transferred to PBS for $24 \mathrm{~h}$ before processing with CRF antibody. After rinsing in fresh PBS four times (10 min each), tissue sections were blocked in $10 \%$ goat serum and $0.1 \%$ Triton X-100 in PBS for $1 \mathrm{~h}$. Sections were then transferred to fresh PBS containing primary antibody for $72 \mathrm{~h}$ at $5^{\circ} \mathrm{C}$. CRF expression was detected using primary rabbit anti-CRF $(\mathrm{T}-$ 4037; $1: 5000,1: 10,000$, or 1:20,000 as determined by pilot experiments; Peninsula Laboratories). As a control to determine whether staining required the presence of the primary antibodies, some sections were run through the assay without primary antibody. After the $72 \mathrm{~h}$ of incubation, the sections were rinsed four times and then processed with Vectastain Elite kits (Vector Laboratories) as per the manufacturer's instructions for standard $\mathrm{ABC} / \mathrm{HRP} /$ diaminobenzidine-based immunohistochemistry. The sections processed for CRF were visualized by reacting the sections with a 3,3'-diamino-benzidine tetrahydrochloride (DAB; Polysciences) reaction solution containing $0.05 \% \mathrm{DAB}, 0.005 \%$ cobalt, $0.007 \%$ nickel ammonium sulfate, and $0.006 \%$ hydrogen peroxide. All sections were mounted on glass slides, air-dried overnight, and coverslipped for viewing. Digital images of each candidate brain region were obtained on an E400 microscope equipped with a Digital Sight DS-U1 digital camera run with manufacturer-provided software (all from Nikon Instruments). CRF-IR was quantified in each region at the level that showed the most robust staining and great care was taken to match sections within each brain region at the same level using anatomic landmarks with the aid of a mouse stereotaxic atlas (Paxinos and Franklin, 2004). Densitometric procedures were used to assess levels of CRF-IR in each brain region. Flat-field corrected digital pictures (8-bit grayscale) were taken using the Digital Sight DS-U1 camera. The density of staining was analyzed using ImageJ software (NIH) by calculating the percent of the total area examined that showed signal (cell bodies and processes) relative to a subthreshold background. To account for differences in background between pictures within the same region, only the darkest area(s) of staining in each image was defined as CRF-IR. Specifically, the darkest area of staining was defined as the first complete cell body to be highlighted by Imagej's threshold function. This cell body and all other areas of staining (including both cell bodies and processes) that were highlighted at this threshold were identified as CRF-IR. Anatomically matched pictures of the left and right sides of the brain were used to produce an average density for each brain region from each slice. In all cases, quantification of immunohistochemistry data was conducted by an experimenter who was blinded to group identity.

Brain slice preparation and electrophysiology. Mice were killed $18-24 \mathrm{~h}$ following ethanol access on day 4 of the final DID cycle and their brains were placed in ice-cold sucrose ACSF containing the following (in $\mathrm{mM}$ ): 194 sucrose, $20 \mathrm{NaCl}, 4.4 \mathrm{KCl}, 2 \mathrm{CaCl}_{2}, 1 \mathrm{Mg} \mathrm{Cl}_{2}, 1.2 \mathrm{NaH}_{2} \mathrm{PO}_{4}, 10.0$ glucose, and $26.0 \mathrm{NaHCO}_{3}$ saturated with $95 \% \mathrm{O}_{2} / 5 \% \mathrm{CO}_{2}$. The brains were cut into $300 \mu \mathrm{m}$ sections using a vibratome and slices containing the CeA were identified using well characterized landmarks such as the BLA. 
A
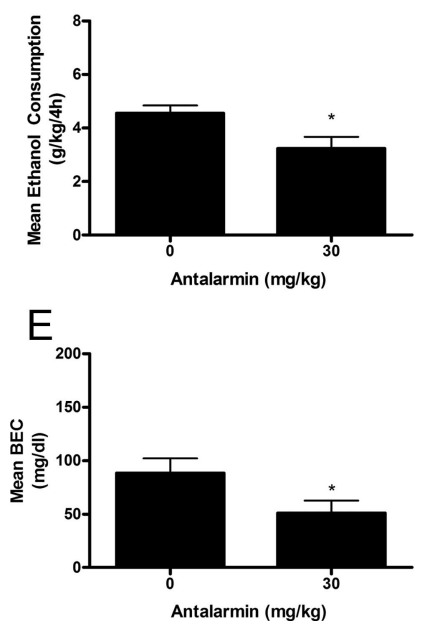

B

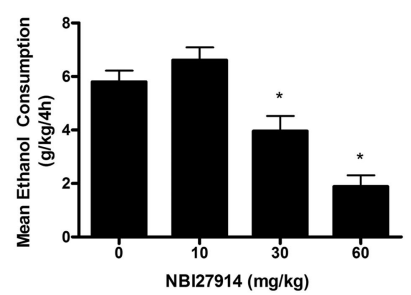

$\mathrm{F}$

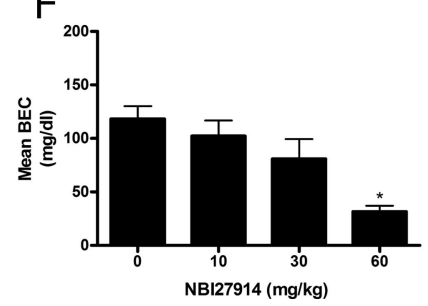

C

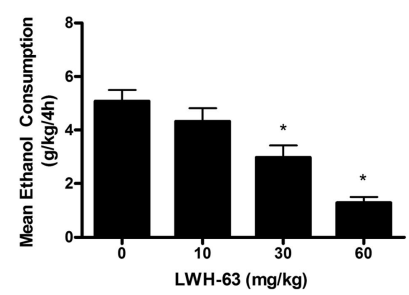

G

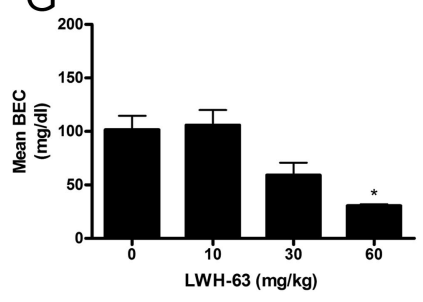

D

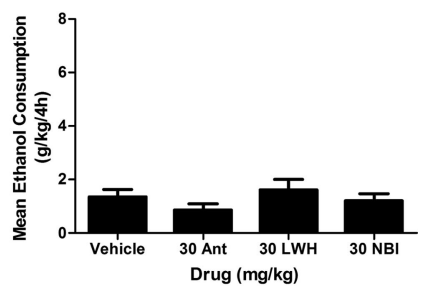

$\mathrm{H}$

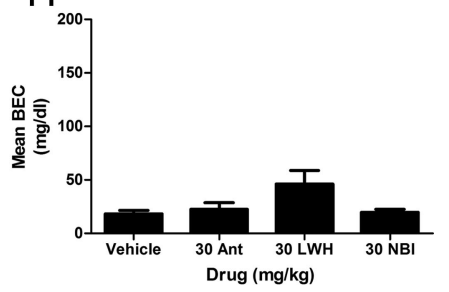

Figure 1. Pretreatment with CRF1R antagonists attenuate binge-like ethanol consumption and BECs but does not alter nonbinge-like ethanol consumption. Antalarmin (30 mg/kg dose) attenuated mean binge-like ethanol consumption $(\boldsymbol{A})$ and mean BECs $(\boldsymbol{E})$. NBI27914 reduced mean binge-like ethanol consumption at the 30 and $60 \mathrm{mg} / \mathrm{kg}$ doses $(\boldsymbol{B})$ and the associated mean BECs at the $60 \mathrm{mg} / \mathrm{kg}$ dose $(\boldsymbol{F})$. LWH-63 (30 and $60 \mathrm{mg} / \mathrm{kg}$ doses) attenuated mean binge-like ethanol consumption ( $\boldsymbol{C}$ ) and the associated mean BECs at the $60 \mathrm{mg} / \mathrm{kg}$ dose (G). $\boldsymbol{D}, \mathrm{Mean}$ nonbinge-like ethanol consumption was not altered by $30 \mathrm{mg} / \mathrm{kg}$ doses of antalarmin, NBI27914, or LWH-63. H, Associated mean BECs were not altered by $30 \mathrm{mg} / \mathrm{kg}$ doses of antalarmin (Ant), NBI27914 (NBI), or LWH-63 (LWH). All data are presented as means \pm SEM, significance was accepted at the $p<0.05$ level, and $n=8-13$ animals per group. * Significant differences from the vehicle group.

Slices were then stored in a heated $\left(28^{\circ} \mathrm{C}\right)$, oxygenated $\left(95 \% \mathrm{O}_{2} / 5 \% \mathrm{CO}_{2}\right)$ holding chamber containing ACSF [ (in mM) $124 \mathrm{NaCl}, 4.4 \mathrm{KCl}, 2 \mathrm{CaCl}_{2}$, $1.2 \mathrm{MgSO}_{4}, 1 \mathrm{NaH}_{2} \mathrm{PO}_{4}, 10.0$ glucose, and $26.0 \mathrm{NaHCO}_{3]}$ or transferred to a submerged recording chamber (Warner Instruments) where they were perfused with heated, oxygenated ACSF at a rate of $2 \mathrm{ml} / \mathrm{min}$. Slices were allowed to equilibrate in ACSF for $1 \mathrm{~h}$ before the start of experiments. Whole-cell voltage-clamp recordings were conducted from slices in the submerged recording chamber. Neurons of the CeA were visualized using infrared video microscopy (Olympus America). Recording electrodes $(3-6 \mathrm{M} \Omega$ ) were pulled on a micropipette puller (Sutter Instruments) using thin-walled borosilicate glass capillaries. To analyze evoked IPSCs (eIPSCs), electrodes were filled with the following (in $\mathrm{mm}$ ): 70 $\mathrm{K}^{+}$-gluconate, $80 \mathrm{KCl}, 10$ HEPES, 1 EGTA, 4 ATP, 0.4 GTP, pH 7.2, 290-295 mOsmol. Twisted nichrome wire stimulating electrodes were placed in the CeA, $100-500 \mu \mathrm{m}$ from the recorded neuron. After entering a whole-cell configuration, cells were held at $-70 \mathrm{mV}$ and GABA type A receptor-mediated IPSCs were evoked at $0.2 \mathrm{~Hz}$ by local fiber stimulation with bipolar electrodes. $\mathrm{GABA}_{\mathrm{A}}$-IPSCs were pharmacologically isolated by adding $10 \mu \mathrm{M}$ NBQX. Signals were acquired via a Multiclamp 700B amplifier (Molecular Devices), digitized, and analyzed via pClamp 10.2 software (Molecular Devices). Input resistance and access resistance were continuously monitored during experiments. Experiments in which changes in access resistance were $>20 \%$ were not included in the data analysis. eIPSC experiments were analyzed by measuring the peak amplitude of the synaptic response, which was normalized to the baseline period. The baseline period was defined as the $2 \mathrm{~min}$ period immediately preceding the application of the drug. CRF (200 nM) was bath applied at minutes 6-20.

Surgery and infusion procedures. Mice were surgically implanted with bilateral 26-gauge guide cannulae (Plastics One) aimed at the CeA (0.94 $\mathrm{mm}$ posterior to bregma; $2.55 \mathrm{~mm}$ lateral to the midline; $2.60 \mathrm{~mm}$ ventral to the skull surface) or the BLA (1.22 mm posterior to bregma; $3.01 \mathrm{~mm}$ lateral to the midline; 4.74 ventral to the skull surface) using the Angle II stereotax (Leica Instruments) with the aid of a mouse stereotaxic atlas (Paxinos and Franklin, 2004). Following surgery, DID procedures were initiated. On day 4 , animals were injected bilaterally with antalarmin (1 $\mu \mathrm{g} / 0.5 \mu \mathrm{l}$ per side) or vehicle ( $5 \%$ emulphor in saline; $0.5 \mu \mathrm{l}$ per side) over a period of $60 \mathrm{~s}$ approximately $1 \mathrm{~h}$ before ethanol access using a 33 -gauge injector designed to extend $2 \mathrm{~mm}$ beyond the cannula tip. A sucrose control study was conducted to evaluate the effects of intra-CeA antalarmin or vehicle on consumption of a $10 \%$ sucrose solution over a $4 \mathrm{~h}$ period beginning $3 \mathrm{~h}$ into the dark portion of the light/dark cycle. For this control study, mice were assigned to drug treatment groups based on their body weights. Cannulae placements were determined for each animal using injections of blue dye and thionin staining of mounted sections of brain tissue. Only the data from mice in which both cannulae were correctly aimed at the CeA or the BLA were included. All data from mice in which both cannulae ( $n=1$ for the CeA; $n=3$ for the BLA) or one cannula ( $n=8$ for the CeA; $n=4$ for the BLA) did not target the CeA or the BLA were excluded.

\section{Statistical analyses}

One-way ANOVAs were used to assess between-group differences in binge-like ethanol consumption and BECs, CRF-IR, and basal GABAergic signaling. Repeated-measures ANOVAs were used to assess eIPSC peak amplitudes before CRF application (minutes 1-5) and while CRF was bath applied (minutes 6-20). A Student's $t$ test was used to assess the main effect of DID treatment on CRF's modulation of GABAergic signaling. As the aim of the immunohistochemistry experiments were to assess the specific effects of binge-like ethanol consumption on CRF-IR, data from animals that did not achieve BECs of $80 \mathrm{mg} / \mathrm{dl}$ or greater are not presented $(n=4)$. Because unquantifiable tissue varied by animal and region in these experiments, the degrees of freedom may differ for each statistical analysis. Tukey's post hoc tests were used to assess specific between-group differences where appropriate. Significance was accepted at the $p<0.05$ (two-tailed). All data are presented as mean \pm SEM.

\section{Results}

\section{Systemic administration of CRF1R antagonists attenuates} binge-like ethanol consumption

To test the hypothesis that high levels of ethanol intake require CRF signaling, the effects of several small molecule, nonpeptide CRF1R antagonists on binge-like ethanol consumption were assessed. Average ethanol consumption and BEC data from day 4 are presented in Figure 1. An ANOVA revealed a significant main effect of antalarmin on binge-like ethanol consumption $\left(F_{(1,25)}=\right.$ $6.548, p=0.017)$, confirming that the $30 \mathrm{mg} / \mathrm{kg}$ dose of antalarmin significantly blunted binge-like ethanol drinking (Fig. $1 A)$. An ANOVA performed on associated BEC data was also significant $\left(F_{(1,25)}=4.296, p=0.049\right)$, as antalarmin-induced reduction of ethanol drinking was associated with a significant reduction of BECs (Fig. $1 E$ ). An ANOVA revealed a significant 
main effect of NBI27914 on binge-like ethanol consumption $\left(F_{(3,37)}=18.512, p<0.001\right)$, and post hoc analyses revealed that pretreatment with the 30 or 60 , but not the $10, \mathrm{mg} / \mathrm{kg}$ doses of NBI27914 significantly attenuated binge-like ethanol consumption relative to vehicle (Fig. $1 B$ ). Similar significant effects were observed on BEC data $\left(F_{(3,37)}=8.048, p<0.001\right)$ and post hoc analyses indicated that pretreatment with $60 \mathrm{mg} / \mathrm{kg}$ resulted in significantly reduced BECs relative to vehicle (Fig. $1 F$ ). An ANOVA revealed a significant main effect of LWH-63 on bingelike ethanol consumption $\left(F_{(3,39)}=13.591, p<0.001\right)$ and post hoc analyses showed that pretreatment with both 30 and 60 $\mathrm{mg} / \mathrm{kg}$ doses of LWH-63 significantly attenuated binge-like ethanol consumption relative to vehicle treatment (Fig. 1C). Similarly, an ANOVA performed on associated BECs was statistically significant $\left(F_{(3,39)}=9.402, p<0.001\right)$ and post hoc analyses indicated that pretreatment with the $60 \mathrm{mg} / \mathrm{kg}$ dose significantly reduced BECs (Fig. 1G). Overall results showed that $30 \mathrm{mg} / \mathrm{kg}$ antalarmin, $30 \mathrm{mg} / \mathrm{kg}$ LWH-63, and $30 \mathrm{mg} / \mathrm{kg}$ NBI27914 selectively altered binge-like ethanol consumption. A $30 \mathrm{mg} / \mathrm{kg}$ dose of antalarmin did not significantly alter sucrose intake (220.76 \pm $20.49 \mathrm{ml} / \mathrm{kg}$ for vehicle-treated mice vs $214.43 \pm 39.67 \mathrm{ml} / \mathrm{kg}$ for antalarmin-treated mice). Furthermore, pretreatment with 30 $\mathrm{mg} / \mathrm{kg}$ doses of LWH-63 or NBI27914 did not significantly alter sucrose drinking $(234.05 \pm 29.30 \mathrm{ml} / \mathrm{kg}$ for vehicle-treated mice vs $267.02 \pm 17.07 \mathrm{ml} / \mathrm{kg}$ for LWH-63-treated mice and $173.48 \pm$ $26.02 \mathrm{ml} / \mathrm{kg}$ for NBI27914-treated mice). These results indicate that CRF1R antagonists selectively modulate binge-like ethanol consumption.

\section{Systemic administration of CRF1R antagonists does not alter nonbinge-like ethanol consumption}

To test the hypothesis that low or moderate levels of ethanol intake do not require CRF signaling, the effects of doses of each of the CRF1R antagonists that altered binge-like ethanol consumption were assessed on nonbinge-like ethanol consumption. An ANOVA assessing the effects of CRF1R antagonists on nonbingelike ethanol consumption data was not statistically significant $\left(F_{(3,34)}=1.068, p=0.377\right.$; Fig. $\left.1 D\right)$. An ANOVA performed on associated BECs was statistically significant $\left(F_{(3,34)}=3.190, p=\right.$ 0.037 ), though post hoc analyses did not indicate any significant differences in BECs between the vehicle group and any of the groups pretreated with a CRF1R antagonist (Fig. $1 H$ ). These results are in agreement with previous investigations showing that CRF1R antagonists have no effect on ethanol consumption that is not preceded by procedures to induce dependence-like drinking (Sabino et al., 2006; Chu et al., 2007; Gehlert et al., 2007) or to induce stress (Marinelli et al., 2007; Lowery et al., 2008), as well as a previous report comparing the effects of the CRF1R antagonist CP-154,526 on binge-like ethanol consumption and nonbingelike ethanol consumption (Sparta et al., 2008; Lowery et al., 2010). Because the Sparta et al. (2008) study also found that a CRF1R antagonist did not alter nonbinge-like ethanol consumption during the dark portion of the light/dark cycle, the lack of effect observed in the current study is unlikely to be due to diurnal effects on CRF (Owens et al., 1990).

CRF-IR is increased immediately following binge-like ethanol drinking and 18-24 $\mathrm{h}$ following the termination of binge-like ethanol drinking

To verify the specificity of our antibody, brain tissue from a CRF wild-type (WT) mouse (Fig. 2A; CeA shown) and a CRF knockout (KO) mouse (Fig. $2 \mathrm{~B}$; CeA shown) was processed with CRF antibody. Importantly, CRF-IR was not observed in the paraven- tricular nucleus of the hypothalamus (PVN), the bed nucleus of the stria terminalis (BNST), the ventral tegmental area (VTA), or the CeA of a CRF KO mouse, but was evident in each of these regions of a CRF WT mouse. The effects of binge-like ethanol consumption on CRF-IR immediately following one (1-cycle) or six (6-cycle) binge-like drinking exposures were investigated to assess the effects of a single episode and multiple episodes of high levels of ethanol intake on central CRF signaling. All comparisons were made with an ethanol-naive group of mice that consumed water for the duration of the experiment (Water). Consumption of ethanol during the $4 \mathrm{~h}$ access period for the duration of the experiment is shown in Table 1. Immediately following the final day of the final DID cycle, the 1-cycle group had mean BECs of $123.28 \pm 12.69 \mathrm{mg} / \mathrm{dl}$ and the 6-cycle group had mean BECs of $161.71 \pm 17.15 \mathrm{mg} / \mathrm{dl}$. The results of a one-way ANOVA confirmed that ethanol consumption and BECs on the final day of the experiment did not differ between DID treatment groups $\left(F_{(1,15)}=0.430, p=0.523\right.$ for ethanol consumption; $F_{(1,14)}=$ 2.657, $p=0.127$ for BECs). Figure 2 shows CRF-IR in the CeA and VTA in DID treatment groups. Binge-like ethanol consumption significantly altered CRF-IR in the CeA $\left(F_{(2,21)}=6.398, p=\right.$ 0.008 ) and post hoc analyses revealed that the 1-cycle and 6-cycle groups had significantly greater CRF-IR than the water group in this region (Fig. 2C-E). A significant effect of binge-like ethanol consumption on CRF-IR in the VTA was also observed $\left(F_{(2,18)}=\right.$ 8.931, $p=0.002$; Fig. 2). Post hoc analyses revealed that the 1 -cycle group displayed significantly greater CRF-IR than the water group and the 6-cycle group (Fig. $2 \mathrm{~F}-\mathrm{H}$ ). CRF-IR was not significantly altered following sucrose consumption in the CeA $(0.10 \pm 0.01 \%$ area for the water group vs $0.15 \pm 0.01 \%$ area for the 1 -cycle group vs $0.15 \pm 0.02 \%$ area for the 6 -cycle group) or in the VTA $(0.05 \pm 0.01 \%$ area for the water group vs $0.06 \pm$ $0.01 \%$ area for the 1 -cycle group vs $0.04 \pm 0.01 \%$ area for the 6 -cycle group). CRF-IR was not significantly altered in any other brain region assessed following binge-like ethanol consumption (Table 2) or following sucrose consumption (data not shown). These results indicate that binge-like ethanol consumption significantly alters CRF-IR of the CeA and the VTA. Because previous studies have primarily assessed the effects of ethanol on CRF expression after ethanol removal (Lowery and Thiele, 2010), we assessed CRF-IR in mice that had undergone three exposures to DID procedures 18-24 h after their final ethanol exposure (3cycle). Ethanol consumption over the course of this experiment is shown in Table 1. Animals of the 3-cycle group achieved mean BECs of $115.8 \pm 20.72 \mathrm{mg} / \mathrm{dl}$ during the final $4 \mathrm{~h}$ ethanol access. A one-way ANOVA revealed that the 3-cycle group had significantly greater CRF-IR in the CeA than the water group did $\left(F_{(1,19)}=7.586, p=0.013\right.$; Fig. $\left.2 I-K\right)$. The resolution of the stain did not allow us to determine whether increases of CRF-IR were due to increases of CRF-IR within cells or an increase in the number of cells exhibiting CRF-IR (or both possibilities). Together, these findings extend those of previous reports showing upregulations of CRF markers in the CeA immediately following chronic ethanol ingestion (Läck et al., 2005) and during acute ethanol withdrawal from chronic intermittent ethanol vapor exposure (Sommer et al., 2008) by demonstrating that similar alterations in CRF-IR are induced by voluntary ethanol consumption that is associated with intoxicating BECs. Additionally, a lack of effect of binge-like ethanol consumption on CRF expression in the PVN corroborates the results of a previous investigation from our group that suggested that binge-like ethanol consumption was modulated by CRF activity outside of the hypothalamic-pituitary-adrenal axis (Lowery et al., 2008). 

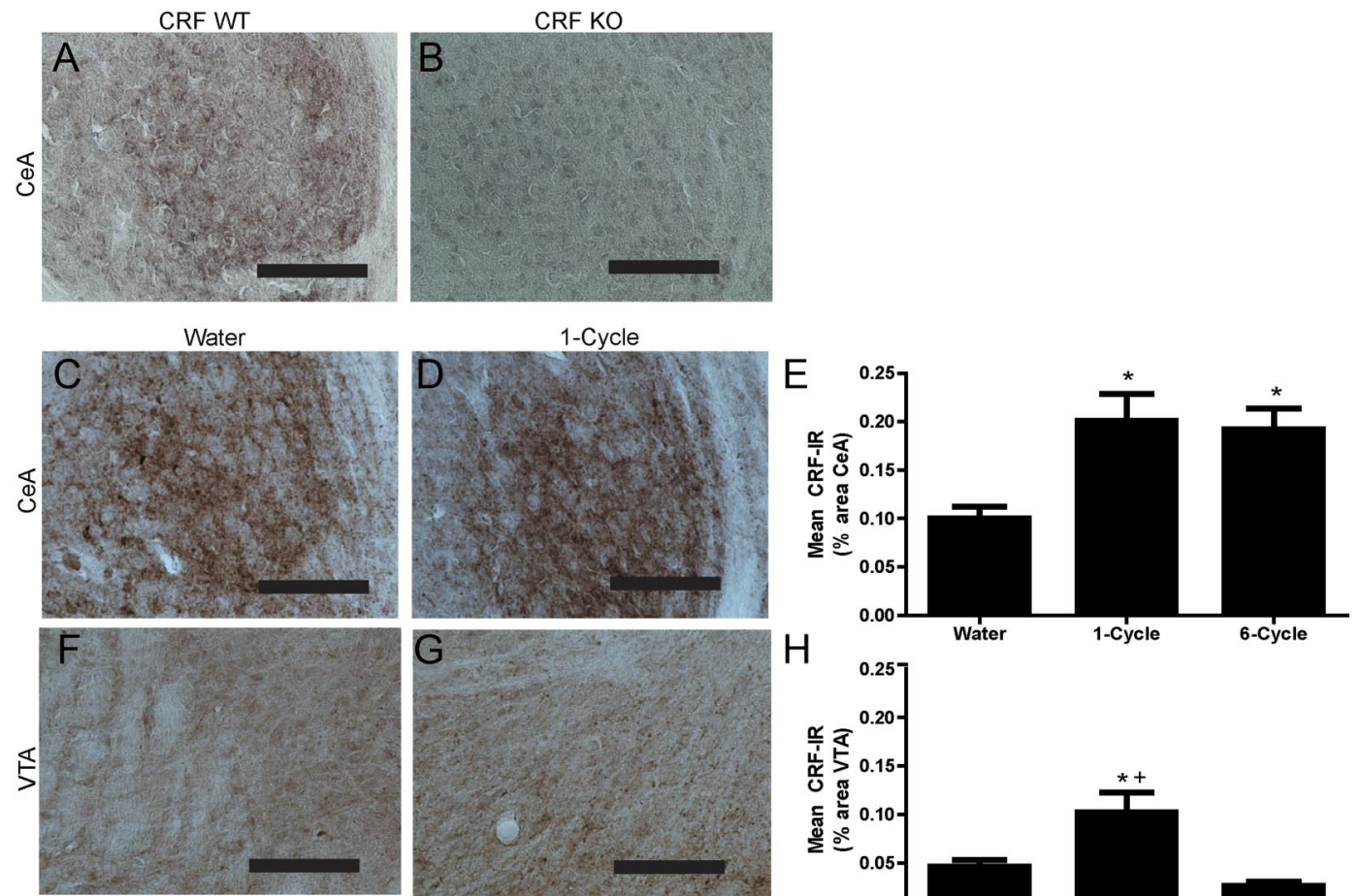

$\mathrm{H}$
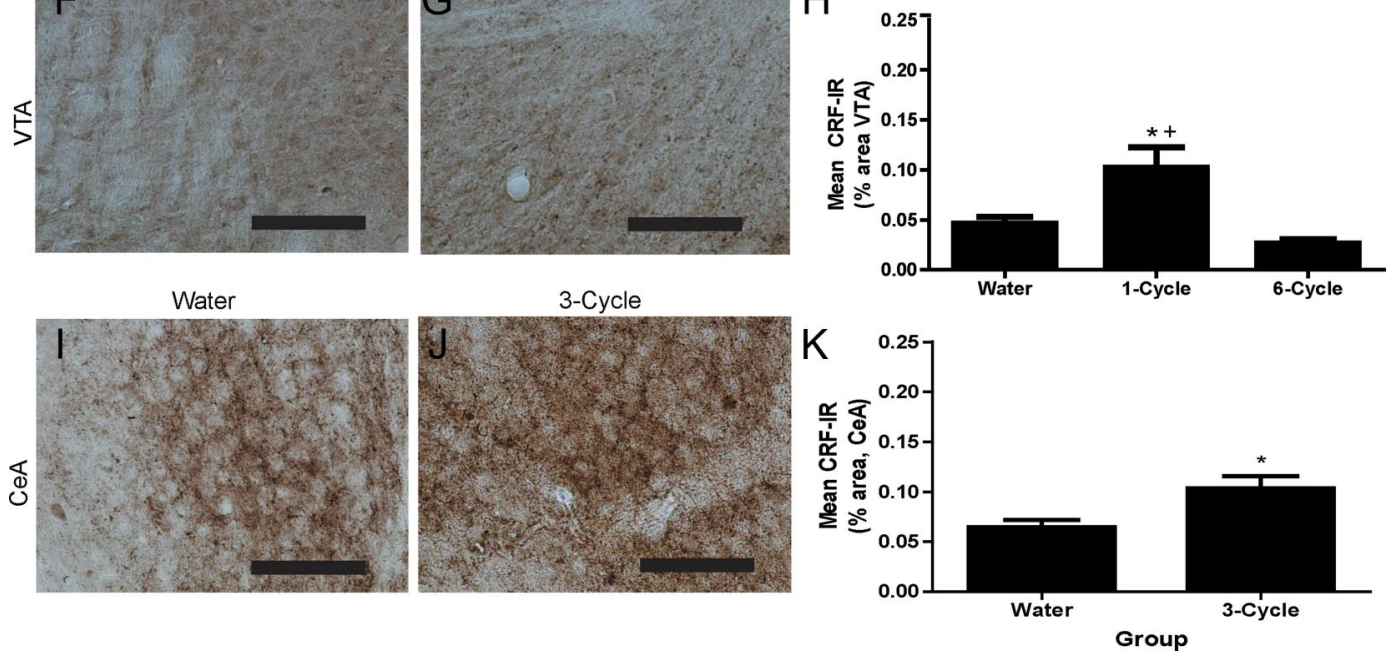

Figure 2. CRF-IR is significantly altered immediately following binge-like ethanol consumption and $24 \mathrm{~h}$ following ethanol removal. Representative photomicrographs demonstrate that the CRF antibody (antibody concentration: 1:20,000) is specific for CRF protein, as CRF-IR was evident in the CeA of a CRF WT mouse ( $\boldsymbol{A}$ ), but was not observed in the CeA of a CRF K0 mouse ( $\boldsymbol{B}$ ). Representative photomicrographs of the CeA $(\boldsymbol{C}, \boldsymbol{D})$ and the VTA $(\boldsymbol{F}, \boldsymbol{G})$ show enhanced CRF-IR (antibody concentration: 1:5000) immediately following ethanol removal in animals exposed to one DID cycle ( $\boldsymbol{D}, \boldsymbol{G}$ ) compared with the water-drinking group $(\boldsymbol{C}, \boldsymbol{F})$. $\boldsymbol{E}$, The 1-cycle and 6-cycle groups had significantly greater mean CRF-IR immediately following ethanol removal in the CeA (percentage of the total area) than the water-drinking group. $\boldsymbol{H}$, The 1-cycle group had significantly greater mean CRF-IR in the VTA (percentage of the total area) immediately following ethanol removal than the water group and the 6-cycle group. $I, J$, Representative photomicrographs of the CeA show CRF-IR (antibody concentration: 1:10,000) in animals of the water group (I) and the 3-cycle group (J) 18 -24 $\mathrm{h}$ following ethanol removal. $\boldsymbol{K}$, The 3-cycle group had significantly greater mean CRF-IR in the (eA (percentage of the total area) than the water group $18-24 \mathrm{~h}$ following their final exposure to ethanol. All data are presented as means \pm SEM, significance was accepted at the $p<0.05$ level, and $n=5-10$ animals per group. ${ }^{*}$, Significant differences from the water group; ${ }^{+}$, significant differences from the 6-cycle group. Scale bars, $50 \mu \mathrm{m}$.

Table 1. Mean binge-like ethanol ( $\mathrm{g} / \mathrm{kg} / \mathrm{h} \mathrm{h} \pm \mathrm{SEM})$ consumption on day 4 of each DID cycle for the duration of each experiment

\begin{tabular}{|c|c|c|c|c|}
\hline \multirow{2}{*}{ 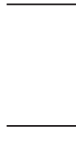 } & \multicolumn{2}{|c|}{$\begin{array}{l}\text { CRF-IR immediately following } \\
\text { binge-like drinking }\end{array}$} & \multirow{2}{*}{$\begin{array}{l}\text { CRF-IR } 18-24 \mathrm{~h} \text { following } \\
\text { binge-like drinking }\end{array}$} & \multirow{2}{*}{$\begin{array}{l}\text { GABAergic transmission } \\
18-24 \mathrm{~h} \text { following } \\
\text { binge-like drinking }\end{array}$} \\
\hline & 1-cycle & 6-cycle & & \\
\hline Cycle 1 & - & $5.62 \pm 0.38$ & $5.37 \pm 0.31$ & $5.64 \pm 0.41$ \\
\hline Cycle 2 & - & $6.02 \pm 0.40$ & $5.39 \pm 0.23$ & $6.07 \pm 0.31$ \\
\hline Cycle 3 & - & $6.01 \pm 0.31$ & $5.27 \pm 0.38$ & $5.27 \pm 0.34$ \\
\hline Cycle 4 & - & $6.70 \pm 0.19$ & - & - \\
\hline Cycle 5 & - & $6.45 \pm 0.31$ & - & - \\
\hline Cycle 6 & $5.81 \pm 0.35$ & $6.63 \pm 0.34$ & - & - \\
\hline
\end{tabular}

The modulatory effects of CRF on GABAergic transmission in the CeA are disrupted following binge-like ethanol drinking Given that alterations of CRF-IR in the CeA were observed $18-24 \mathrm{~h}$ following ethanol removal in mice that had undergone three binge cycles, we hypothesized that multiple episodes of high ethanol intake would result in functional alterations in the CRF system. To maxi- mize the effects of binge history on CRF function and minimize the likelihood of inducing dependence, we assessed the effects of three cycles of binge-like ethanol consumption on the neuromodulatory effects of CRF on GABAergic signaling in the CeA. As we were interested in the effects of a binge history on CRF function regardless of the effects of acute ethanol, this experiment was conducted $18-24 \mathrm{~h}$ following the final binge episode to ensure that ethanol was not on board at the time of testing. Binge-like ethanol consumption on day 4 of each DID cycle is shown in Table 1. Mice of the 3-cycle group achieved mean BECs of $133.48 \pm 10.5$ $\mathrm{mg} / \mathrm{dl}$ during the final $4 \mathrm{~h}$ ethanol access. Representative traces showing the effects of CRF on GABAergic transmission are shown in Figure 3A. The results of a repeated-measures ANOVA revealed that a history of binge-like ethanol exposure lead to a significant reduction in the ability of CRF to enhance GABAergic transmission in the $\operatorname{CeA}\left(F_{(1,9)}=9.163, p=0.014\right.$; Fig. $\left.3 B\right)$. The results of a $t$ test revealed a significant main effect of ethanol history on the average modulation of eIPSC peak amplitude by 
Table 2. Average CRF-IR (percentage area \pm SEM) immediately following binge-like ethanol consumption

\begin{tabular}{|c|c|c|c|c|c|c|c|c|c|c|}
\hline & BLA & MeA & NAccCore & NAccSh & PVN & LH & dIBNST & dmBNST & vBNST & LS \\
\hline Water & $0.02 \pm 0.01$ & $0.07 \pm 0.03$ & $0.06 \pm 0.02$ & $0.05 \pm 0.02$ & $0.11 \pm 0.04$ & $0.07 \pm 0.03$ & $0.15 \pm 0.05$ & $0.08 \pm 0.03$ & $0.06 \pm 0.02$ & $0.07 \pm 0.03$ \\
\hline 1-cycle & $0.02 \pm 0.01$ & $0.08 \pm 0.03$ & $0.06 \pm 0.02$ & $0.09 \pm 0.03$ & $0.09 \pm 0.03$ & $0.07 \pm 0.02$ & $0.13 \pm 0.05$ & $0.10 \pm 0.04$ & $0.06 \pm 0.02$ & $0.08 \pm 0.03$ \\
\hline 6-cycle & $0.02 \pm 0.01$ & $0.09 \pm 0.03$ & $0.10 \pm 0.04$ & $0.15 \pm 0.05$ & $0.14 \pm 0.04$ & $0.10 \pm 0.04$ & $0.21 \pm 0.08$ & $0.12 \pm 0.04$ & $0.06 \pm 0.02$ & $0.13 \pm 0.05$ \\
\hline F-statistic & 0.220 & 0.624 & 2.483 & 2.848 & 1.589 & 1.677 & 1.306 & 1.434 & 0.154 & 2.876 \\
\hline$p$ value & 0.804 & 0.545 & 0.113 & 0.082 & 0.228 & 0.215 & 0.294 & 0.264 & 0.859 & 0.082 \\
\hline
\end{tabular}

MeA, Medial amygdala; NAccCore, nucleus accumbens core; NAccSh, nucleus accumbens shell; LH, lateral hypothalamus; dIBNST, dorsolateral BNST; dmBNST, dorsomedial BNST; vBNST, ventral BNST; LS, lateral septum.

$\operatorname{CRF}\left(t_{(9)}=2.445, p=0.0370\right)$, as the average peak amplitude of IPSCs evoked in the presence of CRF was enhanced by $29 \pm 11 \%$ in water-drinking control mice but was not increased $(-7 \pm 9 \%)$ in mice with a history of binge-like ethanol consumption (Fig. 3C). In addition, to determine whether there were any differences in the probability of basal GABA release, the paired-pulse ratio of the evoked IPSC in both water- and alcohol-exposed mice were assessed, and no significant differences were found $\left(t_{(9)}=0.3392, p=0.74\right.$; Fig. $\left.3 D\right)$. Finally, we evaluated the ability of a CRFR1 antagonist, NBI27914 $(1 \mu \mathrm{M})$, to alter GABAergic transmission in both control and alcohol-exposed mice. This experiment was done to determine whether there was an endogenous CRF tone in the slice related to the ethanol exposure. We found that bath application of NBI27914 had no effect on the peak amplitude of eIPSC in either controls (93 \pm $8 \%$ of baseline, $n=4$ ) or alcohol-exposed mice (108 $\pm 4 \%$ of baseline, $n=3$ ), suggesting that there is no alteration in endogenous CRF tone in the CeA following binge-like ethanol drinking. Together, these results suggest that, despite concomitant upregulations of CRF-IR in this region at the same time point, the modulatory effects of CRF on GABAergic transmission in the CeA are blunted in mice with a history of binge-like ethanol consumption.

\section{Intra-CeA microinjections of a CRF1R antagonist attenuate binge-like ethanol consumption}

Our IR results suggest that CRF signaling may be engaged in the $\mathrm{CeA}$ and motivate binge-like drinking. To test this hypothesis, the effects of microinjections of antalarmin into the CeA on bingelike ethanol consumption were assessed. Average ethanol consumption and BEC data from day 4 are presented in Figure 4 . The results of a one-way ANOVA revealed a significant effect of drug treatment $\left(F_{(1,14)}=8.921, p=0.011\right)$, confirming that intra-CeA administration of antalarmin significantly blunted binge-like ethanol consumption (Fig. 4A). Significant between-group differences in BECs were also observed $\left(F_{(1,14)}=4.847, p=0.046\right)$, as mice pretreated with antalarmin achieved significantly lower BECs than mice that received vehicle (Fig. $4 B$ ). Conversely, pretreatment with antalarmin into the CeA did not have effects on 4 h sucrose consumption $\left(F_{(1,16)}=1.458, p=0.246\right.$; Fig. $\left.4 C\right)$. Cannula placements are shown in Figure $4 D$. These results dem-

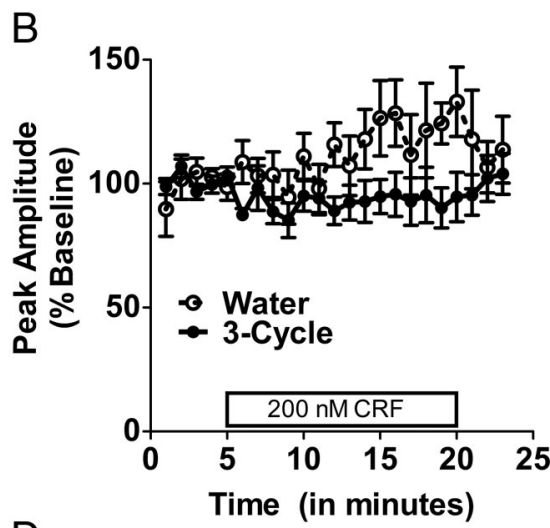

$\mathrm{D}$

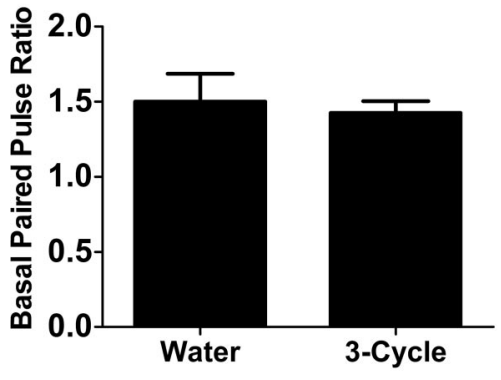

Figure 3. The modulation of GABAergic transmission by CRF in the CeA is disrupted $18-24 \mathrm{~h}$ following binge-like ethanol consumption. $\boldsymbol{A}$, Representative traces show that CRF significantly enhanced eIPSCs relative to baseline IPSCs in a slice from the water group (left), an effect which was abolished in a slice from the 3-cycle group (right). $\boldsymbol{B}$, Bath application of (RF to slices (he 3-cycle group. C, Bath application of CRF enhanced elPSC peak amplitudes of the water group by $>20 \%$, but did not alter the (h-cycle group. $\boldsymbol{D}$, The water and 3-cycle groups did not differ in basal paired-pulse ratio. All data are presented as means \pm SEM, significance was accepted at the $p<0.05$ level, and $n=5-6$ cells per group (recordings taken from a single cell from each animal). ${ }^{*}$, Significant differences from the water group.

onstrate that binge-like ethanol consumption, like dependencelike ethanol consumption (Funk et al., 2006), requires CRF signaling in the CeA and are the first to demonstrate a direct role for CRF1Rs in this region in ethanol consumption (Lowery and Thiele, 2010).

Intra-BLA microinjections of a CRF1R antagonist do not alter binge-like ethanol consumption

To determine whether the effects of microinjections of antalarmin into the CeA on binge-like ethanol consumption could have resulted from diffusion of the drug to other regions of the amygdala, we also assessed the effects of microinjections of antalarmin into the BLA, a region proximal to the CeA and dense in CRF1R expression (Hauger et al., 2006), on binge-like ethanol consumption. Average ethanol consumption and BEC data from day 4 are presented in Figure 4. The results of a one-way ANOVA indicated no significant main effect of drug treatment on bingelike ethanol consumption $\left(F_{(1,16)}=1.124, p=0.306\right.$; Fig. $\left.4 E\right)$ or BECs $\left(F_{(1,16)}=0.082, p=0.778\right.$; Fig. $\left.4 F\right)$. Cannula placements are shown in Figure $4 G$. These results suggest that the attenuation 

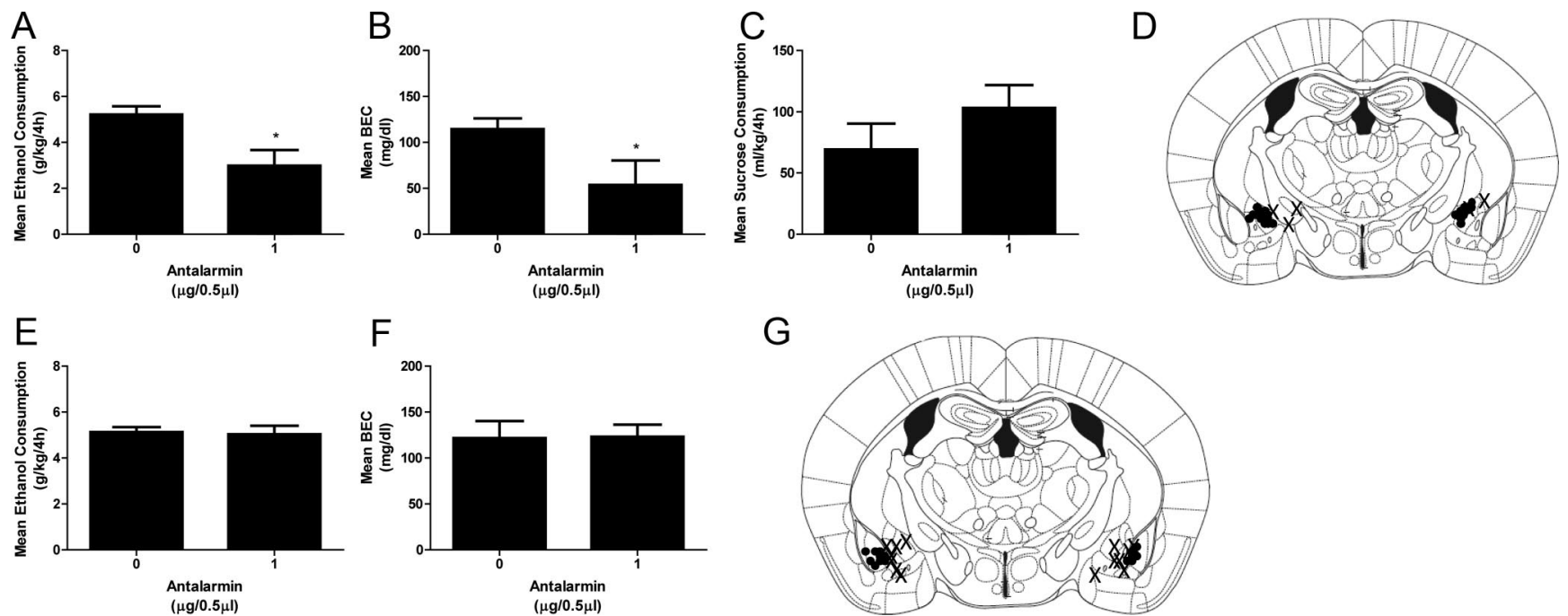

$\mathrm{F}$

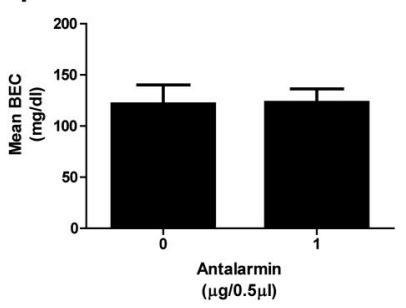

G

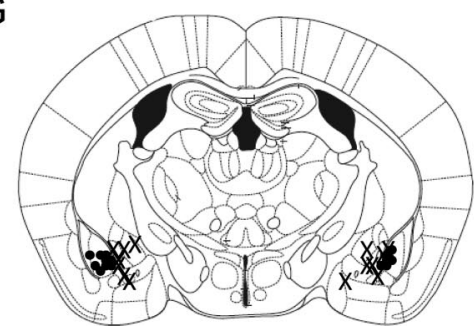

Figure 4. Pretreatment with a CRF1R antagonist in to the CeA, but not the BLA, attenuates binge-like ethanol consumption and BECs. $A-C$, Antalarmin (1.0 $\mu g / 0.5 \mu$ l per side) attenuated mean binge-like ethanol consumption $(\boldsymbol{A})$ and mean $\mathrm{BECS}(\boldsymbol{B})$, but did not alter mean consumption of a sucrose solution ( $\boldsymbol{C}$ ). $\boldsymbol{D}$, Correct cannulae placements (i.e., bilateral placements targeting the $(\mathrm{C} A)$ are marked with black circles, and incorrect cannulae placements (i.e., unilateral placements targeting the CeA or no placements targeting the CeA) are marked with an " $X$ ". $E$, $F$, When injected into the BLA, antalarmin (1.0 $\mu \mathrm{g} / 0.5 \mu$ l per side) did not alter mean binge-like ethanol consumption (E) or mean BECs (F). $\mathbf{G}$, Correct cannulae placements (i.e., bilateral placements targeting the BLA) are marked with black circles, and incorrect cannulae placements (i.e., unilateral placements targeting the BLA or no placements targeting the BLA) are marked with an " $X$ ". All data are presented as means \pm SEM, significance was accepted at the $p<0.05$ level, and $n=5-9$ correct placements per group. ${ }^{*}$, Significant differences from the vehicle group.

of binge-like ethanol consumption by intra-CeA administration of antalarmin was not likely to be due to diffusion of the drug into the BLA.

\section{Discussion}

The results of the current study provide novel evidence that endogenous CRF signaling is recruited in the CeA during bouts of binge-like ethanol consumption. First, three selective CRF1R antagonists reduced binge-like ethanol consumption at doses that did not alter nonbinge-like ethanol intake. Second, a history of binge-like ethanol drinking was associated with a significant increase of CRF-IR in the CeA and in the VTA. Additionally, a history of binge-like ethanol drinking abolished the ability of exogenous CRF to increase GABAergic transmission in the CeA at a time point when endogenous CRF-IR was upregulated in the same region. Finally, antagonism of CRF1R in the CeA, but not in the BLA, attenuated binge-like ethanol consumption. These converging results show that binge-like ethanol consumption recruits CRF1R signaling in the CeA, which is necessary for maintaining excessive binge-like ethanol intake.

\section{CRF1Rs and ethanol consumption}

Previous investigations comparing the effects of CRF1R antagonists on binge-like ethanol consumption to their effects on nonbinge-like ethanol consumption (Sparta et al., 2008; Lowery et al., 2010) have shown that CRF1R antagonists reduce high levels of ethanol consumption without effects on moderate or low levels of ethanol consumption (for review, see Lowery and Thiele, 2010). Similarly, CRF1R antagonists attenuate elevated ethanol consumption stemming from procedures to induce dependence-like drinking (for review, see Lowery and Thiele, 2010), stress (Marinelli et al., 2007; Lowery et al., 2008; Sommer et al., 2008), and deprivation-induced drinking (Sparta et al., 2009). Additionally, CRF1R antagonists attenuate ethanol consumption by the selectively bred Marchigian Sardinian alcoholpreferring rats (Ciccocioppo et al., 2006; Gehlert et al., 2007). Thus, while these compounds are effective under conditions that elicit high levels of ethanol consumption, CRF1R antagonists do not alter moderate levels of ethanol consumption by nonstressed, nonselected animals in which dependence-like drinking has not been established (for review, see Lowery and Thiele, 2010). Together, these data may suggest that high levels of ethanol consumption that promote pharmacologically relevant BECs (i.e., $\geq 80 \mathrm{mg} / \mathrm{dl}$ ) recruit CRF signaling, while moderate or low levels of ethanol consumption (associated with low BECs) do not. Interestingly, the role of CRF in cocaine self-administration also appears to be intake-dependent, as escalated cocaine selfadministration by animals with a history of high cocaine intake was attenuated by CRF1R antagonists at doses that did not alter cocaine self-administration by animals with a history of low cocaine intake (Specio et al., 2008). Thus, the hypothesis that the recruitment of CRF is dependent on the amount of ethanol consumed during a given period of access may also extend to other drugs of abuse.

\section{Ethanol's effects on CRF-IR}

Ethanol-induced alterations in CRF signaling in regions such as the CeA have previously been noted. Specifically, previous investigations have demonstrated significantly augmented CRF mRNA in the CeA of animals immediately following chronic ethanol ingestion (Läck et al., 2005) and in ethanol-dependent animals during acute withdrawal (Sommer et al., 2008). Additionally, increases in extracellular CRF were suggested in the CeA of ethanol-dependent animals during acute withdrawal, as decreases in total CRF-IR, but no change in the total number of CRF-immunoreactive cell bodies, were observed relative to nondependent animals (Funk et al., 2006). Our data extend the current literature by demonstrating that CRF-IR in the CeA is altered by high levels of ethanol consumption in animals with little (i.e., one binge-like drinking cycle) or moderate (i.e., six binge-like drinking cycles) ethanol exposure. This is an important observation because it suggests that recruitment of CRF signaling in the CeA during early binge-like drinking episodes, before dependence, may trigger initial neuroplastic changes in this system. 
Theoretically, these changes may become more robust and rigid with repeated binge-like drinking experiences, contributing to the transition to dependence. Though increases of CRF-IR may reflect increased CRF activity (via increased CRF synthesis and/or release) or decreased CRF activity (via decreased CRF release), our converging pharmacological and electrophysiological results strongly suggest that CRF activity is elevated during binge-like ethanol consumption.

We also observed changes in CRF-IR in the VTA following a single binge-like drinking cycle. Previous studies have implicated CRF signaling in the VTA in the modulation of stress-induced reinstatement to cocaine seeking (Wang et al., 2005, 2007), which may be due to CRF's neuromodulatory effects on dopaminergic and glutamatergic transmission within this region (Wise and Morales, 2010). Thus, administration of CRF or a CRF1R agonist directly into the VTA significantly reinstated cocaine-seeking by animals that had undergone long access to cocaine selfadministration (Blacktop et al., 2011). Notably, intra-VTA administration of CRF did not alter stress-induced reinstatement to cocaine-seeking by animals that had undergone short access to cocaine self-administration, suggesting that CRF of the VTA modulates drug-taking behavior only in animals with a history of high cocaine intake. As ethanol has known actions on dopaminergic and glutamatergic systems of the VTA (Stuber et al., 2008), in addition to the CeA, binge-like ethanol drinking may also be modulated by CRF in the VTA.

\section{Ethanol's effects on CRF-induced GABAergic transmission in the CeA}

In the CeA, CRF exerts modulatory effects on GABAergic signaling via CRF1Rs in a way that mirrors ethanol's effects on GABAergic transmission (Nie et al., 2009; Roberto et al., 2010). The current data and previous work (Roberto et al., 2010) show that CRF enhances GABAergic transmission by neurons of the CeA in ethanol-naive animals. Previous investigations have shown that relative to ethanol-naive controls, this effect is augmented by chronic intermittent exposure to alcohol vapor (Roberto et al., 2010). However, we found that a history of binge-like ethanol consumption abolished the ability of CRF to enhance GABAergic transmission. Relative to water-drinking controls, we observed a blunted response to bath-applied CRF in brain slices of mice that experienced three binge-like drinking cycles at a time point when they also had increased CRF-IR in the CeA. This may reflect homeostatic regulation of the CRF-GABA system in response to high synaptic CRF concentrations (e.g., internalization of CRF receptors). Alternatively, upregulated tonic activity of CRF may have occluded the effect of subsequently applied CRF. However, this is unlikely given that there was no difference in basal pairedpulse ratio between water-drinking mice and mice that experienced three cycles of binge-like ethanol drinking (which would be expected if CRF was already active) and the lack of an effect of the CRFR1 antagonist on evoked GABAergic transmission.

The divergent results of the current study and previous studies of animals exposed to ethanol vapor suggest that binge-like ethanol consumption engenders different patterns of GABAergic transmission than does ethanol dependence, evidenced by differences in responses to exogenous CRF in the CeA between animals that experienced procedures to induce dependence-like drinking and nondependent animals with a history of binge-like ethanol intake, and by the observation that a history of binge-like drinking did not alter baseline GABAergic transmission as has been described in vapor-exposed rats (Roberto et al., 2010). It is important to consider factors that may have contributed to the dif- ferences between dependence-like and binge-like drinking models noted above. Few exposures to high levels of ethanol (as in the current study) may cause transient perturbations of the CRF system that return to a homeostatic set point, while many exposures to high levels of ethanol (as in studies of ethanoldependent animals) may cause long-lasting adaptations in the CRF system that reflect the establishment of an allostatic set point. Interestingly, the disruption of CRF signaling found in the present report is similar to what was seen in the closely related structure, the BNST, following chronic cocaine exposure (Nobis et al., 2011), as repeated cocaine exposure led to a transient disruption in CRFR1 modulation of excitatory transmission with no changes in basal synaptic properties. Also consistent with our data is a study demonstrating that stress leads to an internalization of CRFR1 receptor in the dorsal raphe (Waselus et al., 2009). It is important to note that while binge-like ethanol consumption and dependence-induced ethanol consumption appear to fundamentally differ in some aspects, behaviors require CRF signaling in the CeA.

\section{Conclusions and future directions}

The results of the current study suggest that CRF signaling in the $\mathrm{CeA}$ is critical for the expression of binge-like drinking behavior. CRF signaling in the CeA is recruited during excessive ethanol intake, before the development of dependence, and we speculate that plastic changes in CRF signaling within the CeA develop over the course of repeated binge-like drinking episodes, contributing to alterations in critical downstream targets like the BNST ( $\mathrm{Li}$ et al., 2012), and ultimately to the transition to ethanol dependence. Future investigations will examine potential differences in the CRF systems of binge-like drinking relative to nonbinge-like drinking mice and will elucidate the effects of binge-induced modifications of CRF activity in the CeA on downstream targets. Our observations suggest that compounds aimed at CRF1R may have therapeutic value for treating excessive binge drinking, perhaps protecting vulnerable individuals from progressing to dependence.

\section{References}

Blacktop JM, Seubert C, Baker DA, Ferda N, Lee G, Graf EN, Mantsch JR (2011) Augmented cocaine seeking in response to stress or CRF delivered into the ventral tegmental area following long-access self-administration is mediated by CRF receptor type 1 but not CRF receptor type 2. J Neurosci 31:11396-11403.

Chu K, Koob GF, Cole M, Zorrilla EP, Roberts AJ (2007) Dependenceinduced increases in ethanol self-administration in mice are blocked by the CRF1 receptor antagonist antalarmin and by CRF1 receptor knockout. Pharmacol Biochem Behav 86:813-821.

Ciccocioppo R, Economidou D, Cippitelli A, Cucculelli M, Ubaldi M, Soverchia L, Lourdusamy A, Massi M (2006) Genetically selected Marchigian Sardinian alcohol-preferring (msP) rats: an animal model to study the neurobiology of alcoholism. Addict Biol 11:339-355.

Finn DA, Snelling C, Fretwell AM, Tanchuck MA, Underwood L, Cole M, Crabbe JC, Roberts AJ (2007) Increased drinking during withdrawal from intermittent ethanol exposure is blocked by the CRF receptor antagonist d-phe-CRF(12-41). Alcohol Clin Exp Res 31:939-949.

Funk CK, O'Dell LE, Crawford EF, Koob GF (2006) Corticotropin-releasing factor within the central nucleus of the amygdala mediates enhanced ethanol self-administration in withdrawn, ethanol-dependent rats. J Neurosci 26:11324-11332.

Gehlert DR, Cippitelli A, Thorsell A, Lê AD, Hipskind PA, Hamdouchi C, Lu J, Hembre EJ, Cramer J, Song M, McKinzie D, Morin M, Ciccocioppo R, Heilig M (2007) 3-(4-chloro-2-morpholin-4-yl-thiazol-5-yl)-8-(1-ethylpropyl)2,6-dimethyl-imidazo[1,2-b]pyridazine: a novel brain-penetrant, orally available corticotropin-releasing factor receptor 1 antagonist with efficacy in animal models of alcoholism. J Neurosci 27:2718-2726. 
Hauger RL, Risbrough V, Brauns O, Dautzenberg FM (2006) Corticotropin releasing factor (CRF) receptor signaling in the central nervous system: new molecular targets. CNS Neurol Disord Drug Targets 5:453-479.

Hayes DM, Knapp DJ, Breese GR, Thiele TE (2005) Comparison of basal NPY and CRF levels between the high ethanol drinking C57BL/6J and low ethanol drinking DBA/2J inbred mouse strains. Alcohol Clin Exp Res 29:721-729.

Heilig M, Thorsell A, Sommer WH, Hansson AC, Ramchandani VA, George DT, Hommer D, Barr CS (2010) Translating the neuroscience of alcoholism into clinical treatments: from blocking the buzz to curing the blues. Neurosci Biobehav Rev 35:334-344.

Jennison KM (2004) The short-term effects and unintended long-term consequences of binge drinking in college: a 10-year follow-up study. Am J Drug Alcohol Abuse 30:659-684.

Ji G, Fu Y, Ruppert KA, Neugebauer V (2007) Pain-related anxiety-like behavior requires CRF1 receptors in the amygdala. Mol Pain 3:13.

Kim KS, Han PL (2009) Mice lacking adenylyl cyclase-5 cope badly with repeated restraint stress. J Neurosci Res 87:2983-2993.

Koob GF (2003) Alcoholism: allostasis and beyond. Alcohol Clin Exp Res 27:232-243.

Koob GF (2009) Brain stress systems in the amygdala and addiction. Brain Res 1293:61-75.

Läck AK, Floyd DW, McCool BA (2005) Chronic ethanol ingestion modulates proanxiety factors expressed in rat central amygdala. Alcohol 36:83-90.

Li C, Pleil KE, Stamatakis AM, Busan S, Vong L, Lowell BB, Stuber GD, Kash TL (2012) Presynaptic inhibition of gamma-aminobutyric acid release in the bed nucleus of the stria terminalis by kappa opioid receptor signaling. Biol Psychiatry. Advance online publication. doi:10.1016/j.biopsych.2011.11.015.

Lowery EG, Thiele TE (2010) Pre-clinical evidence that corticotropinreleasing factor $(\mathrm{CRF})$ receptor antagonists are promising targets for pharmacological treatment of alcoholism. CNS Neurol Disord Drug Targets 9:77-86.

Lowery EG, Sparrow AM, Breese GR, Knapp DJ, Thiele TE (2008) The CRF-1 receptor antagonist, CP-154,526, attenuates stress-induced increases in ethanol consumption by BALB/cJ mice. Alcohol Clin Exp Res $32: 240-248$

Lowery EG, Spanos M, Navarro M, Lyons AM, Hodge CW, Thiele TE (2010) CRF-1 antagonist and CRF-2 agonist decrease binge-like ethanol drinking in C57BL/6J mice independent of the HPA axis. Neuropsychopharmacology 35:1241-1252.

Marinelli PW, Funk D, Juzytsch W, Harding S, Rice KC, Shaham Y, Le AD (2007) The CRF(1) receptor antagonist antalarmin attenuates yohimbine-induced increases in operant alcohol self-administration and reinstatement of alcohol seeking in rats. Psychopharmacology (Berl) 195:345-355.

McCarty CA, Ebel BE, Garrison MM, DiGiuseppe DL, Christakis DA, Rivara FP (2004) Continuity of binge and harmful drinking from late adolescence to early adulthood. Pediatrics 114:714-719.

National Institute on Alcohol Abuse and Alcoholism (2004) NIAAA council approves definition of binge drinking. NIAAA Newsletter 3:3.

Nie Z, Zorrilla EP, Madamba SG, Rice KC, Roberto M, Siggins GR (2009) Presynaptic CRF1 receptors mediate the ethanol enhancement of GABAergic transmission in the mouse central amygdala. ScientificWorldJournal 9:68-85.

Nobis WP, Kash TL, Silberman Y, Winder DG (2011) beta-Adrenergic receptors enhance excitatory transmission in the bed nucleus of the stria terminalis through a corticotrophin-releasing factor receptor-dependent and cocaine-regulated mechanism. Biol Psychiatry 69:1083-1090.

Owens MJ, Bartolome J, Schanberg SM, Nemeroff CB (1990) Corticotropinreleasing factor concentrations exhibit an apparent diurnal rhythm in hypothalamic and extrahypothalamic brain regions: differential sensitivity to corticosterone. Neuroendocrinology 52:626-631.

Paxinos G, Franklin KBJ (2004) The mouse brain in stereotaxic coordinates, compact 2nd edition. Boston: Academic.

Read JP, Beattie M, Chamberlain R, Merrill JE (2008) Beyond the "binge" threshold: heavy drinking patterns and their association with alcohol involvement indices in college students. Addict Behav 33:225-234.
Rhodes JS, Best K, Belknap JK, Finn DA, Crabbe JC (2005) Evaluation of a simple model of ethanol drinking to intoxication in C57BL/6J mice. Physiol Behav 84:53-63.

Rhodes JS, Ford MM, Yu CH, Brown LL, Finn DA, Garland T Jr, Crabbe JC (2007) Mouse inbred strain differences in ethanol drinking to intoxication. Genes Brain Behav 6:1-18.

Roberto M, Cruz MT, Gilpin NW, Sabino V, Schweitzer P, Bajo M, Cottone P, Madamba SG, Stouffer DG, Zorrilla EP, Koob GF, Siggins GR, Parsons LH (2010) Corticotropin releasing factor-induced amygdala gammaaminobutyric acid release plays a key role in alcohol dependence. Biol Psychiatry 67:831-839.

Roberts AJ, Heyser CJ, Cole M, Griffin P, Koob GF (2000) Excessive ethanol drinking following a history of dependence: animal model of allostasis. Neuropsychopharmacology 22:581-594.

Robison CL, Meyerhoff JL, Saviolakis GA, Chen WK, Rice KC, Lumley LA (2004) A CRH1 antagonist into the amygdala of mice prevents defeatinduced defensive behavior. Ann N Y Acad Sci 1032:324-327.

Sabino V, Cottone P, Koob GF, Steardo L, Lee MJ, Rice KC, Zorrilla EP (2006) Dissociation between opioid and CRF1 antagonist sensitive drinking in Sardinian alcohol-preferring rats. Psychopharmacology (Berl) 189:175-186.

Sommer WH, Rimondini R, Hansson AC, Hipskind PA, Gehlert DR, Barr CS, Heilig M (2008) Upregulation of voluntary alcohol intake, behavioral sensitivity to stress, and amygdala Crhrl expression following a history of dependence. Biol Psychiatry 63:139-145.

Sparta DR, Sparrow AM, Lowery EG, Fee JR, Knapp DJ, Thiele TE (2008) Blockade of the corticotropin releasing factor type 1 receptor attenuates elevated ethanol drinking associated with drinking in the dark procedures. Alcohol Clin Exp Res 32:259-265.

Sparta DR, Ferraro FM 3rd, Fee JR, Knapp DJ, Breese GR, Thiele TE (2009) The alcohol deprivation effect in C57BL/6J mice is observed using operant self-administration procedures and is modulated by CRF-1 receptor signaling. Alcohol Clin Exp Res 33:31-42.

Specio SE, Wee S, O’Dell LE, Boutrel B, Zorrilla EP, Koob GF (2008) CRF(1) receptor antagonists attenuate escalated cocaine self-administration in rats. Psychopharmacology (Berl) 196:473-482.

Stahre MA, Brewer RD, Fonseca VP, Naimi TS (2009) Binge drinking among U.S. active-duty military personnel. Am J Prev Med 36:208-217.

Stuber GD, Hopf FW, Hahn J, Cho SL, Guillory A, Bonci A (2008) Voluntary ethanol intake enhances excitatory synaptic strength in the ventral tegmental area. Alcohol Clin Exp Res 32:1714-1720.

Thiele TE, Roitman MF, Bernstein IL (1996) c-Fos induction in rat brainstem in response to ethanol- and lithium chloride-induced conditioned taste aversions. Alcohol Clin Exp Res 20:1023-1028.

Thiele TE, van Dijk G, Bernstein IL (1997) Ethanol-induced c-Fos expression in rat lines selected for low and high alcohol consumption. Brain Res 756:278-282.

Thiele TE, Cubero I, van Dijk G, Mediavilla C, Bernstein IL (2000) Ethanolinduced c-Fos expression in catecholamine- and neuropeptide Y-producing neurons in rat brainstem. Alcohol Clin Exp Res 24:802-809.

Wang B, Shaham Y, Zitzman D, Azari S, Wise RA, You ZB (2005) Cocaine experience establishes control of midbrain glutamate and dopamine by corticotropin-releasing factor: a role in stress-induced relapse to drug seeking. J Neurosci 25:5389-5396.

Wang B, You ZB, Rice KC, Wise RA (2007) Stress-induced relapse to cocaine seeking: roles for the $\mathrm{CRF}(2)$ receptor and CRF-binding protein in the ventral tegmental area of the rat. Psychopharmacology (Berl) 193:283-294.

Wang J, Fang Q, Liu Z, Lu L (2006) Region-specific effects of brain corticotropin-releasing factor receptor type 1 blockade on footshockstress- or drug-priming-induced reinstatement of morphine conditioned place preference in rats. Psychopharmacology (Berl) 185:19-28.

Waselus M, Nazzaro C, Valentino RJ, Van Bockstaele EJ (2009) Stressinduced redistribution of corticotropin-releasing factor receptor subtypes in the dorsal raphe nucleus. Biol Psychiatry 66:76-83.

Wise RA, Morales M (2010) A ventral tegmental CRF-glutamate-dopamine interaction in addiction. Brain Res 1314:38-43. 